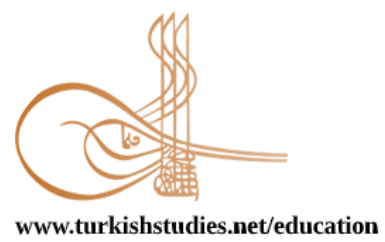

www.turkishstudies.net/education
Turkish Studies - Educational Sciences

eISSN: 2667-5609

Research Article / Araștırma Makalesi

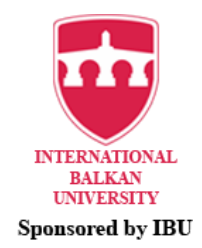

Sponsored by IBU

\title{
Türkçenin Yabancı Dil Olarak Öğretiminde Çokluk Eki
}

Plural Suffix In Teaching Turkish As A Foreign Language

\author{
Şeyda Yeşilyurt*
}

\begin{abstract}
Teaching Turkish as a foreign language differs from teaching Turkish as a mother tongue. While the students who learn the rules of Turkish as their mother tongue do not question the attachments, the students who learn a new language question all the attachments and try to realize the meaning that the word adds to the sentence. The plural suffix is one of the appendices questioned by students who learn Turkish as a foreign language. Students find it difficult to understand some grammatical structures for example "abimler/ abilerim", "arkadaşımlar( it is false)/ arkadaşlarım" and ask why. In this study, two textbooks prepared to teach Turkish to foreign students to find solutions to these questions and previous studies on the teaching of plural suffixes to foreign students are examined. While the previous study on the multiplicity attachment focuses on the language level of the supplement, the point that is particularly noteworthy in this study is not the order of the plural suffix in the grammar order in the textbooks; the different meaning features that the annex adds to the word should be included in language teaching. In the study, it is emphasized in the textbooks how to teach the plural suffix, in which language level, in which subject and how to do it, especially in the teaching of suffixes, a grammar classification based on comprehension and multidimensionality (forgiveness) of the suffixes is required. . Some of the topics covered in grammar books should be given at a basic level, and should be elaborated at other levels as the language level of the student develops. It can be difficult and unnecessary to explain and teach the basic level of the exaggeration of the lAr suffix to the student, but it is imperative to teach that the- 1 Ar suffix adds different meanings to the word to which the student is added. In addition, although grammar is not a skill, it is a support that makes it easier to learn and teach a foreign language. Since the structure and grammatical priority of each language are different from each other, a standard ranking should be made by considering the structure of the Turkish language in grammar teaching.
\end{abstract}

Structured Abstract: Introduction: Each language family has its own grammatical structure. Turkish, like other languages in the Ural-Altaic language family, has an additive structure. Thanks to this structure, new words are derived by bringing different additions to the fixed word roots and the feature of being a living being of the language can be observed. The suffixes brought to the words are classified as inflexional and constructional suffixes, the formal functions of the suffixes are emphasized and semantic functions are pushed to the secondary plan in the teaching stage. Although some inflexional suffixes act as constructional suffixes depending on their meaning in the sentence and the word they are added to, but these tasks are generally ignored during the teaching of these suffixes. One of these suffixes is "-lar" plural. In this study,

\footnotetext{
* Dr., Gazi Üniversitesi TÖMER

Dr., Gazi University, Turkish Teaching Center for Foreigner (TÖMER)

ORCID 0000-0001-7721-5323

seydayesilyurt82@gmail.com

Cite as/ Atıf: Yeşilyurt, Ş. (2020). Türkçenin yabancı dil olarak öğretiminde çokluk eki. Turkish Studies - Education, 15(3), 2211-2224. https://dx.doi.org/10.29228/TurkishStudies.40120

Received/Geliş: 11 December/Aralık 2019

Accepted/Kabul: 21 June/Haziran 2020

Checked by plagiarism software

Copyright (C) INTAC LTD, Turkey

Published/Yayin: 25 June/Haziran 2020

CC BY-NC 4.0
} 
how the plural suffix "-lar" in books written for the purpose of teaching Turkish as a foreign language will be evaluated and the adequacy of the expression in the books will be emphasized.

\section{Conceptual Framework}

We can classify the meaning features that the plural suffix adds to the name it comes from:

a) Meaning of Plural and Family

b) Exaggeration Meaning

c) Meaning of "Every" (Generalization)

d) Similarity Meaning

e) Meaning of Approximation

f) Respect Meaning

g) Meaning of Remembering the Past

h) Meaning of Emotions like Surprise, Reproach

i) Meaning of Being in the Same Ideology

j) Biological General Name Meaning

k) Meaning of Year Expression

1) Place Name That Made of Persons and Titles

\section{Method}

This research is a descriptive study using a screening model. In this research qualitative data collection techniques were used. In the research, the data were collected by using document analysis method. Document analysis method, to reach the resources for the purpose of the research and will be obtained used to determine the data (Çepni, 2007: 76). Thus examined The books provided us with information about the subject.

\section{Working Group}

The study group of this research consists of the chapters related to the teaching of the plural suffix in "İstanbul Turkish Textbook A1 for Foreigners " and " Yedi İklim Turkish A1" which are used in teaching Turkish to foreigners.

\section{Purpose of the research}

The aim of the research is to examine the sufficiency of plural suffix in the Yedi İklim Türkçe and İstanbul Turkish Textbook for Foreigners A1, which is one of the textbooks teaching Turkish to foreigners and to discuss whether this information is sufficient.

\section{İstanbul Yabancılar İçin Türkçe (A1):}

The description of the plural annex is located on page 15 in the "Hello" first unit. "Alphabet- Bu-SuO / Kim-Ne / Multiple Attachment / Question Attachment / Where Is This" is the grammar order of unit 1. The variation of the thickness (-lar/-s) in the thickness, fineness harmony is shown in the table. The signal pronouns "these, those, they" are given in plural form. Plural forms of words ending with thick and thin vowels are exemplified. In the first subject, "İyi akşamlar, teşekkürler, tebrikler, iyi yolculuklar, bol şanslar, mutlu yıllar, iyi geceler, iyi seneler, nice senelere, sonsuz mutluluklar, anneler günün kutlu olsun anneciğim" mold expressions were given before the instruction of the plural suffix.

The thickness and fineness of the crop are shown in the table and examples are given. The cases where the suffix is not used and the exception words are also given in a table and the students are asked to add plural suffix to the given words. 


\section{Yedi İklim Türkçe Ders Kitabı (A1):}

Yedi İklim Turkish Textbooks, like other sets written to teach Turkish to foreigners, consist of two books at A basic level, two at B intermediate level and two courses at C advanced level (in some sets there is only one book at advanced level). In this set, the plural suffix is given in the basic level A 1 textbook. The task of the plural suffix was tried to be sensed with examples, and a small table (a, 1, o, u-s; e, i, ö, ü-s) was shown without any information (p.29). Then, four visuals were given and the students were expected to write the singular and plural forms of the names in these images. The subject is given after the teaching of "numbers", and after the adjectives that declare a plural, it is tried to be sensed with the example that no plural suffix is used. Before the subject of plural, the text was "molded", "'iyi günler, iyi akşamlar, and iyi geceler in a dialogue "Hoşça kalın kızlar!" expression. Unlike the book İstanbul, the subject "pronouns" is in the other unit.

The difficulties experienced by students who learn Turkish as a foreign language in terms of plural suffix at A basic level; not knowing when to use bold when thin vowel, the exception is to mix the use of words with plural suffix, to use the plural suffix after some adjectives specifying numbers and indefiniteness. In addition, "Arkadaşlarım ve Arkadaşımlar" mistake is a common mistake of most students. When they came to the middle and advanced level " dayımlar ve dayılarım " to be able to distinguish between, " Fatihler bize geldi " using the apostrophe with the special name in sentences such as to punctuate the wrong. The plural suffix emphasizes the function of making plural names especially when teaching the mother tongue Turkish as well as the students who learn Turkish as a foreign language. (saat-ler, harf-ler, sembol-ler... and number of adjectives after the adjectives appear to be used. When the books prepared for teaching Turkish as a foreign language are examined, it is seen that this determination is correct.

\section{Conclusion and Suggestions}

In this study, the study of the plural suffix in books written for teaching Turkish as a foreign language was examined and the missing points were tried to be determined. In addition, it was tried to be searched in different books dealing with the plural suffix, and how the plural suffix was used from the past to the present has been found in the book called "Türk Dilinde Çokluk" of İlhan (2009). In another study on the plural suffix in teaching Turkish to foreıgners (Kılıç et al .: 2014), it was found that "Yeni Hitit Yabancilar İçin Türkçe" and "Lale Yabancılar İçin Türkçe Ders Kitabı" were examined. As a result of this study, it is emphasized that there should be unity between the sources in order to give the plural suffix among the grammar subjects. Although we agree with the previous study on this subject, the point that we want to draw attention to in this study is not that the plural suffix should be given in grammar rankings; the additional meaning that the suffix adds to the word should be given in language teaching. The expression of the plural suffix in the Yeni Hitit and Lale books is similar to the "İstanbul and Yedi İklim" books. Other functions of the supplement are not described in these books. However, a problem is encountered here. It is both difficult and unnecessary for the basic level to explain the other meaning features of the plural suffix to a foreign student who is learning Turkish at A basic level. Linguistics also emphasizes the structure-meaning-function dimensions in the language in the context of foreign language teaching by approaching multilayered language studies (Erdem, Çelik: 2011).

Some grammar rules have a forked structure. While it is possible to explain the basic part of the fork at A basic level, we have to give the other meaning features or functions of the fork at different levels. For this reason, the grammar rules in this structure, especially the plural suffix, should be determined and the grammar rules should be revised especially in teaching Turkish to foreigners so that the basic rules are at the basic level and the other functions are at different levels. Students should be taught before the end of the intermediate level in which the multiplicity suffix is not used after some uncharacteristic adjectives (hiç hiçbir, birkaç, az - biraz, çok - birçok, çoğu, her, herhangi bir)). Other meaning features of the suffix should be given to the students especially after the family meaning (-gil), exaggeration meaning, approximation meaning, year meaning after the possessive suffix. In the teacher's guide books of the book sets written for teaching Turkish to foreigners, emphasis should be placed on the multidimensionality of the suffix and the levels at which the different functions of the suffix will be given. In fact, the same teaching should be applied according to the level of Turkish students. The questions asked to the students in the fifth grade of the primary school and the students of the last grade of the high school contain the same vocabulary, the rules are tried to be given in the same way, which is heavy for the younger children. 
Although grammar is not a skill, it is a support that facilitates the learning and teaching of a foreign language. Since the structure and grammatical priority of each language is different from each other, a standard ranking should be made considering the structure of Turkish language in grammar teaching (Yeşilyurt, 2018). In this ranking, the meaning features of the structures should be taken into consideration, which meaning feature will be given to foreigners in teaching Turkish and at what level should be discussed and a common decision should be made.

Keywords: teaching Turkish as a foreign language, plural suffix, grammar, Turkish teaching books for foreigners, A1 level.

Öz: Türkçenin yabancı dil olarak öğretimi, Türkçenin ana dili olarak öğretiminden farklılık arz etmektedir. Ana dili olarak Türkçenin kurallarını öğrenen öğrenciler, ekleri sorgulamazken yeni bir dil öğrenen öğrenciler bütün ekleri sorgulamakta; ekin kelimeye, cümleye kattığı anlamı fark etmeye çalışmaktadırlar. Çokluk eki de Türkçeyi yabancı bir dil olarak öğrenen öğrencilerin sorguladığı eklerden biridir. Neden "arkadaşımlar" değil de "arkadaşlarım"; eğer doğrusu "arkadaşlarım" sa neden "abimler" doğru gibi kendilerince mantıklı sorular yönelterek ekin kelimeye kattığı anlamı ve dilin yapısını anlamaya çalışmaktadırlar. Bu çalışmada, bu sorulara çözüm bulmak amacıyla yabancı öğrencilere Türkçe öğretmek amacıyla hazırlanmış iki ders kitabı ve çokluk ekinin yabancı öğrencilere öğretimiyle ilgili daha önce yapılmış çalışmalar incelenmektedir. Çokluk ekiyle ilgili daha önce yapılan çalışma, ekin hangi dil seviyesinde verildiği üzerinde yoğunlaşmaktayken bu çalışmada özellikle dikkat çekilmek istenen nokta, çokluk ekine, ders kitaplarında dil bilgisi sıralamasında hangi sırada yer verilmesi gerektiği değil; ekin kelimeye kattığı farklı anlam özelliklerinin de dil öğretiminde yer alması gerektiğidir. Çalışmada ders kitaplarında çokluk ekinin öğretiminin nasıl yapıldığı, hangi dil seviyesinde, hangi konu içinde verildiği ve nasıl yapılması gerektiği üzerinde durulmakta, özellikle eklerin öğretiminde öğrencilerin dil seviyelerinin göz önünde bulundurularak anlama ve eklerin çok boyutluluğuna(çatallılığına) dayalı bir dil bilgisi tasnifi yapılması gerektiğine vurgu yapılmaktadır. Dil bilgisi kitaplarında ele alınan bazı konular temel seviyede verildikten sonra öğrencinin dil seviyesi geliştikçe diğer seviyelerde detaylandırılarak verilmelidir. -lAr çokluk ekinin abartma anlamını, temel seviyedeki öğrenciye anlatmak ve öğretmek zor ve gereksiz olabilir ancak öğrencinin seviyesi ilerledikçe -1Ar ekinin eklendiği kelimeye farklı anlamlar da kattığını öğretmek bir zorunluluktur. Ayrıca dil bilgisi bir beceri olmasa da yabancı bir dilin öğrenilmesini ve öğretilmesini kolaylaştıran bir destektir. Her dilin yapısı ve dil bilgisel önceliği birbirinden farklı olduğu için dil bilgisi öğretiminde Türk dilinin yapısı düşünülerek standart bir sıralamaya gidilmelidir.

Anahtar Kelimeler: Türkçenin yabancı dil olarak öğretimi, çokluk eki, dil bilgisi, yabancılar için Türkçe öğretim kitapları, A1 dil seviyesi.

\section{Giriş}

Her dil ailesinin kendine has bir gramer yapısı vardır. Türkçe, mensubu olduğu Ural-Altay dil ailesindeki diğer diller gibi sondan eklemeli bir yapıya sahiptir. Bu yapı sayesinde sabit kalan kelime köklerine farklı ekler getirilerek yeni kelimeler türetilmekte dilin canlı bir varlık olma özelliği gözlenebilmektedir. Kelimelere getirilen ekler, çekim ve yapım eki olarak sınıflandırılmakta, öğretim aşamasında eklerin daha çok biçimsel fonksiyonları üzerinde durulmakta ve anlamsal fonksiyonları ikinci plana itilmektedir. Bazı ekler de çekim eki olmalarına rağmen cümledeki ve eklendikleri kelimedeki anlamlarına bağlı olarak yapım eki görevi üstlenmekte ancak bu eklerin öğretimi sırasında bu görevleri genellikle göz ardı edilmektedir. Bu eklerden biri de "-1Ar" çokluk ekidir. Bu çalışmada Türkçenin yabancı dil olarak öğretimi amacıyla yazılan kitaplarda "-lAr" çokluk ekinin nasıl ele alındığı değerlendirilerek kitaplardaki anlatımın yeterliliği üzerinde durulacaktır.

\section{Kavramsal Çerçeve}

Aynı cinsten birden çok varlıkları anlatmak istediğimiz zaman adların sonuna bir -lAr eki getiririz; ağaçlar, kumlar, kazlar... Bu hâldeki adları da çoklu(pluriel) diye anarız (Banguoğlu, 1998:322). Çekim ekleri birleştiği kök veya gövdenin manasında bir değişiklik yapmaz. Kök ve 
gövdeye bir işleklik, kök ve gövdenin manasına bir kullanış nüansı verir. Muharrem Ergin(2005:221), çokluk ekinin kullanımı konusunda, "Çokluk eki, şümulü en dar olan işletme ekidir. Şümulüne isimlerin yalnız teklik şekli girer. Demek ki çokluk ekinden sonra iyelik, hâl ve soru ekleri gelebilmekte, fakat iyelik, hâl ve soru eklerinden sonra çokluk eki getirilememektedir." demek suretiyle, ekin kendisinden sonra isim çekim eklerinin kullanılabildiklerini ancak Türkçenin kelime çekimi ve eklerin kullanım sırasına göre de çokluk ekinin iyelik, hâl ve soru eklerinden sonra kullanılmadığını da belirtmektedir. Yine Ergin(2005:221) "Yalnız iyelik birinci ve ikinci şahıs eklerinden sonra bugün çokluk ekinin bazen getirildiği görülmekte, bu ise yukarıda yapım eklerinde gördügümüz gibi -gil ekinin yerini tutan hususî bir kullanıştan ibaret bulunmaktadır: babam-lar, annem-ler gibi." diyerek ekin iyelik ekinden sonraki kullanımını da vurgulamıştır.

Çoğul ekinin eklendiği isme kattığı anlam özellikleri hakkında Doğru (2017), $+\{1 \mathrm{Ar}\}$ biçimbirimi en işlek işlevi olan "adlarda çokluk yapma" işlevinin yanında çeşitli işlevlerle karşımıza çıkabilmektedir. Bunlardan bir tanesi de yer aldığı tümcelerde "dilek/temenni” bildirme işlevidir. Bu işlev çoğunlukla ilişki sözleri olan kalıp sözlerde (tatlı rüyalar, merhabalar, sıhhatler olsun) görülmektedir, demektedir. Yabancılara Türkçe öğretiminde çokluk eki üzerine yapılan başka bir çalışmada (Kılıç vd.: 2014) da "Yeni Hitit Yabancılar İçin Türkçe" ve "Lale Yabancılar İçin Türkçe Ders Kitabı" incelendiği tespit edilmiş, incelenen kitaplardaki dil bilgisi anlatımında görülen sıralama farklılıklarının üzerinde durulduğu görülmüsştür. Bu çalışmada Ergin (2005), Korkmaz (2003), Banguoğlu (1998), İlhan (2009) ve Doğru'dan (2017) (temenni anlamı için ayrı bir başlık açılmamıştır) hareketle çokuluk ekinin anlam özellikleri üzerine bir sınıflandırma yapılmıştır ve şu şekildedir:

\section{1. Çokluk ve Aile Anlamı (Dayılarım/ Dayımlar )}

İsim çekim eki göreviyle kullanılan çokluk eki ( -1Ar) 'nin esas görevi, adları ve ad soylu sözcükleri çoğullaştırmaktır. Ek, fiillerde şahıs eki göreviyle kullanıldığı zaman yine çokluk anlamı katmakta, işi yapan kişi sayısının birden fazla olduğunu belirtmektedir. Korkmaz (2003, 255), isimlerde ve zamirlerde aynı türden birden çok varlığ 1 anlatmak için; fiillerde, fiilin gösterdiği oluş ve kılışı yapın, yani şahsın çokluk olduğunu göstermek için kullanılan özel eklerin arasında çokluk ekine dair örnekler göstermektedir: ağaç + lar, çiçek + ler, oda + lar, bey + ler, okul + umuz, bahçe + lerimiz, biz+ ler, on + lar, gidecek-ler.. Çokluk eki Türkçede hem sayılabilen hem sayılamayan isimlerle kullanılabilir. Sayılan isimlere kattığı anlamlar, çalışmanın devamında geniş̧e ele alınacaktır. Sayılamayan isimlere ise (elektrikler, havalar...) kuvvetlendirme anlamının yanında ismin farklı yer ya da zamanlardaki durumunu kapsayan bir çokluk anlamı katmaktadır:

Ankara'da dün elektrikler yoktu (Tek bir ilçe ya da semtte değil, Ankara'nın tümünü ya da genelini kapsayan bir durum).

Havalar da serin gidiyor (Bugünkü hava durumu değil, haftalık ya da aylık hava durumu).

"Dayımlar" örneğinde olduğu gibi eğer çokluk eki akrabalık bildiren isimlerde iyelik ekinden sonra kullanılırsa "-gıl/-gil" ekinin kattı̆̆ anlamı katmakta, "aile" anlamı vermektedir: Teyzemler (teyzemgil), amcamlar (amcamgil), halamlar (halamgil), dedemler (dedemgil)... Çokluk eki, akrabalık isimlerinin yanında özel isimlerle birlikte kullanıldığı zamanda aile anlamı katabilmektedir: Mehmetler bugün evde yoklar.( Mehmetler $=$ Mehmetgil). Ekin cümledeki kullanımına bağlı olarak çokluk anlamı da katabileceği unutulmamalıdır: Sınıftaki Mehmetler bugün yoklardı (Sınıfta çok sayıda Mehmet adında öğrenci bulunmaktadır.).

Başlıkta "çokluk ve aile anlamı"nı birlikte ele almamızın nedeni, ekin öğretiminde ikisi arasındaki farka dikkat çekilmemesi ve bundan dolayı öğrencilerin iki çokluk arasındaki anlam farkını ayırt edememesidir. Öğretimde, çokluk ekinin iyelik ekinden önce geldiği belirtilmekte ancak iyelik ekinin çokluk ekinden önce kullanıldığı yerde, nasıl bir anlam ilgisi kurduğu belirtilmemektedir. 


\subsection{Abartma Anlamı}

Anlamı kuvvetlendirmek için bir şeyi olduğundan daha fazla ya da daha az gösterme sanatı olarak bilinen "abartma" için de "daha fazla" gösterme amacıyla çokluk ekinden faydalanılır.

Adamın durumu içler acısı, evlatları bile arayıp sormuyormuş. (iç-ler)

Dünyalar güzeli bir insan, mutlaka onunla tanışmalısın.( dünya-lar)

Beni ne mühendisler ne doktorlar istedi de evlenmedim. (mühendis-ler/ doktor-lar; ayrica meslek grubu anlamı da vardır)

\section{3. "Her (Genelleme)" Anlamı}

Kuznetsov (1997) "-1Ar” ekinin genelleme anlamı katan eski yapı özelliğinin "akşamları, sabahları, yazları..." gibi örneklerde korunduğunu belirterek, ekin son ünlüsünün (-1ArI / -1Ar) sonradan düştüğünü ifade etmektedir. Kuznetsov'un da belirttiği gibi zaman belirten isimlere “1Ar" eki geldiğinde her ya da genelleme anlamı katmaktadır.

Akşamları deniz kenarında oturup sohbet ederdik. (akşamları= her akşam)

Yazları buralar bir başka güzel olur. (yazları=her yaz)

\subsection{Benzerlik Anlamı}

Çokluk eki, meşhur kişi isimlerine eklendiği zaman isme "onun gibi” anlamı katmaktadır.

Türk anaları daha nice Fatihler yetiştirecektir. (Fatih Sultan Mehmet gibi)

Bu vatanın Yunusları da Mevlanaları da bitmez. (Yunus Emre ve Mevlana gibi)

\subsection{Yaklaşıklık Anlamı}

Sayılarla ilgili kelimelerle birlikte çokluk eki yaklaşıklık anlamı katmaktadır.

Sabaha doğru dört sularında büyük bir gürültüyle yataktan firladık. (dört civarında)

Dün kırk yaşlarında bir bey sizi sordu. (yaklaşık kırk yaşında)

\subsection{Saygı Anlamı}

Özel isimlerin yanına eklenen bey, hanım gibi unvan özelliği taşıyan isimlerle birlikte kullanıldığında çokluk eki saygı anlamı katmaktadır:

Kerem Beyler, henüz toplantıya başlamadılar.

Avukat Hanımlar beş dakika içinde burada olurlar.

Sizler benim için çok değerlisiniz.

\subsection{Geçmiş Zamanı Hatırlama Anlamı}

Geçmişteki günleri hatırlama amacıyla zaman bildiren kavramlarla "-1Ar” eki yine çokluk anlamını da koruyacak şekilde kullanılmaktadır. katmaktadır.)

Bir zamanlar evimizin önünde inekler yayılırdı. (Bir zamanlar, eskiden anlamı

Hey gidi günler hey! Az mı koşturduk şu parklarda!

\section{8. Şaşırma, Sitem Gibi Duygu Anlamı}

Çokluk eki, bazen özel isimler ve unvanlarla kullanıldığında kelimeye bir duygu (sitem, küçümseme, alay, şaşırma...) anlamı katabilmektedir.

Ooo Ayşe Hanımlar da buradaymış! (şaşıma, alay içeren bir anlam) 
Beyefendiler en sonunda evin yolunu bulmuşlar! (Kızma anlamı)

\subsection{Soy, Millet, Devlet Anlamı}

Özel isimlerle kullanıldığı zaman soy, millet, devlet anlamı verebilmektedir.

Selçuklular, Anadolu'nun Türkleşmesinde en büyük rolü oynamışlardır. (Selçuklu Devleti) Devleti)

Osmanlılar, geçmişimize olduğu kadar geleceğimize yön veren bir pusuladır. (Osmanlı

\subsection{Ayn İdeolojiye Mensup Olma Anlamı}

Aynı din, aynı görüşten olan topluluğu belirtmek amacıyla da çokluk eki kullanılmaktadır:

Atatürkçüler, Cumhuriyet'e sahip çıkmalıdır.

Müslümanlar, sadece Allah rızasını gözetmek için yaşarlar.

\subsection{Biyolojik Genel Ad Anlamı}

Hayvan, bitki gibi canlı türleriyle ilgili adlandırmalar için çokluk eki kullanılmaktadır:

Sürüngenler, memeliler, tek hücreliler, baklagiller...

Sürüngenler, yumurtlayarak çoğalan hayvanlardır.

\subsection{Yıl İfadesi Anlamı}

Çokluk eki yıl ifade eden sayılarla kullanıldığında on yıllık bir zaman aralığını ifade edebilmektedir.

1980'ler herkesin hafizasında farklı bir yer sahiptir. (1980’ler/ seksen-doksan aralığındaki y1llar kastedilmektedir.)

Televizyon 1990'larda evlerimize yeni yeni girmeye başlayan bir yabanciyken bugün ev sahibi konumunda evlerimize kurulmuştur. (90'l1 yıllar)

\subsection{3. Şahıs ve Unvanlardan Yapılmış Yer Adı Anlamı}

Çokluk eki şahıs isimleriyle veya unvan isimleriyle birlikte kullanılarak yerleşim adları oluşturmaktadır.

Bağcılar'dan kalkan otobüs Avcılar'a doğru hareket etti. (Bağcılar, Avcılar)

\section{Yöntem}

$\mathrm{Bu}$ araştırma, tarama modeli kullanılan betimsel bir çalışmadır. Araştırma nitel veri toplama tekniklerinden faydalanılarak gerçekleştirilmiştir. Tarama modelleri, geçmişte ya da hâlen var olan bir durumu var olduğu şekliyle betimlemeyi amaçlayan araştırma yaklaşımlarıdır. Araştırmaya konu olan olay, birey ya da nesne, kendi koşulları içinde ve olduğu gibi tanımlanmaya çalışılır. Onları herhangi bir şekilde değiştirme, etkileme çabası gösterilmez. Bilinmek istenen şey vardır ve oradadır. Önemli olan, uygun bir biçimde "gözleyip" belirleyebilmektir (Karasar, 2010: 77). Olayların, objelerin, varlıkların, kurumların, grupların ve çeşitli alanların ne olduğunu betimlemeye, açıklamaya çalışır. Bu sayede onları iyi anlayabilme, gruplayabilme olanağı sağlanır ve aralarındaki ilişkiler saptanmış olur (Kaptan, 1998). Araştırmada verilerin toplamasında doküman analizi yöntemi kullanılmıştır. Doküman analizi yöntemi, araştırmanın amacına yönelik kaynaklara ulaşmada ve elde edilecek verilerin tespit edilmesinde kullanılır (Çepni, 2007: 76). Böylece incelenen kitaplar konunun ele alınışı hakkında bilgi sahibi olmamızı sağlamıştır.

\section{4. Çalışma Grubu}


$\mathrm{Bu}$ araştırmanın çalışma grubunu yabancılara Türkçe öğretiminde kullanılan "İstanbul Yabancılar İçin Türkçe Ders Kitabı A1" ve "Yedi İklim Türkçe A1" kitaplarındaki çokluk ekinin ögretimiyle ilgili bölümler oluşturmaktadır.

\section{Araştırmanın Amacı}

Yabancılara Türkçe öğretim ders kitaplarından Yedi İklim Türkçe Ders Kitabı ile ve İstanbul Yabancılar İçin Türkçe Ders Kitabı A1'de çokluk ekinin ele alınışını incelemek ve Türkçenin yabancı dil olarak öğretimi için yazılan diğer kitaplarla "çokluk eki"nin verillişi yönünden aralarında farklılık olup olmadığını belirlemektir.

\section{Bulgular}

$\mathrm{Bu}$ bölümde araştırma sonucundan elde edilen bulgulara ve yorumlara yer verilmektedir. Burada öncelikle "Yedi İklim Türkçe" ve "İstanbul Yabancılar İçin Türkçe" ders kitapları hakkında "çokluk eki" ni ele alışları yönünden genel bilgi verilmektedir. Ardından bu iki kitap ve çokluk eki üzerine yapılan diğer çalışmadaki (Kılıç vd.: 2014) iki kitabın bulgularına yer verilmekte, bu kitaplardaki bilgiler karşılaştırmalı olarak ele alınmaktadır.

İstanbul Yabancılar İçin Türkçe (A 1) Ders Kitabı:

Çokluk ekinin anlatımı, "Merhaba" 1. ünite içerisinde sayfa 15'te yer almaktadır. "AlfabeBu-Şu-O/ Kim-Ne/ Çoğul Eki/ Soru Eki/ Burası Neresi" 1. ünitenin dil bilgisi sıralamasıdır. Kalınlık, incelik uyumunda ekin ( -lar/ -ler) değișimi tablo ile gösterilmiștir. İşaret zamirlerinin "bunlar, şunlar, onlar" çokluk şekli verilmiştir. Son hecesi kalın ve ince ünlü ile biten kelimelerin çokluk şekilleri örneklendirilmiştir. İlk konuda "İyi akşamlar, teşekkürler, tebrikler, iyi yolculuklar, bol şanslar, mutlu y1llar, iyi geceler, iyi seneler, nice senelere, sonsuz mutluluklar, anneler günün kutlu olsun anneciğim" kalıp ifadeleri, çokluk ekinin öğretiminden önce verilmiştir.

Çoğul Eki (-IAr) (Plural Suffix)
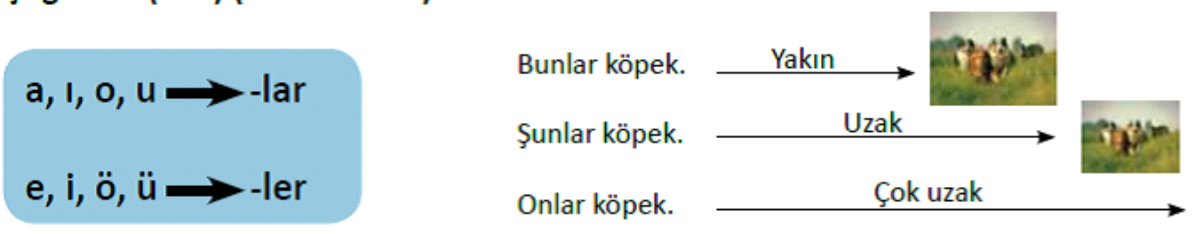

\begin{tabular}{|l|l|l|l|}
\hline Tekil & Çoğul & Tekil & Çoğul \\
\hline kitap & kitaplar & pencere & pencereler \\
\hline kız & kızlar & kedi & kediler \\
\hline kutu & kutular & köy & köyler \\
\hline televizyon & televizyonlar & üzüm & üzümler \\
\hline
\end{tabular}

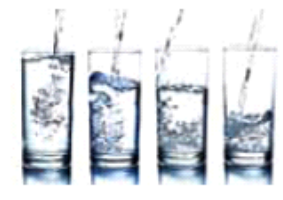

Bunlar ne(dir)? Bunlar bardak(tor). Bardaklar.
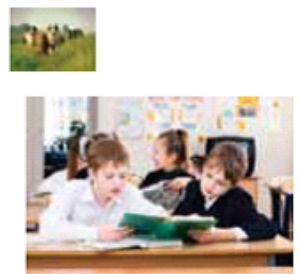

Bunlar kim(dir)? Bunlar öğrenci(dir). Öğrenciler.

İstanbul Yabancılar İçin Türkçe Ders Kitabı, s. 15

Ekin kalınlık incelik uyumu tablo ile gösterildikten sonra örnekler verilmiştir. Ekin kullanılmadığı durumlar ve istisna kelimeler de yine bir tablo ile verilmiş, öğrencilerden verilen kelimelere çokluk eki getirmeleri istenmiştir. 


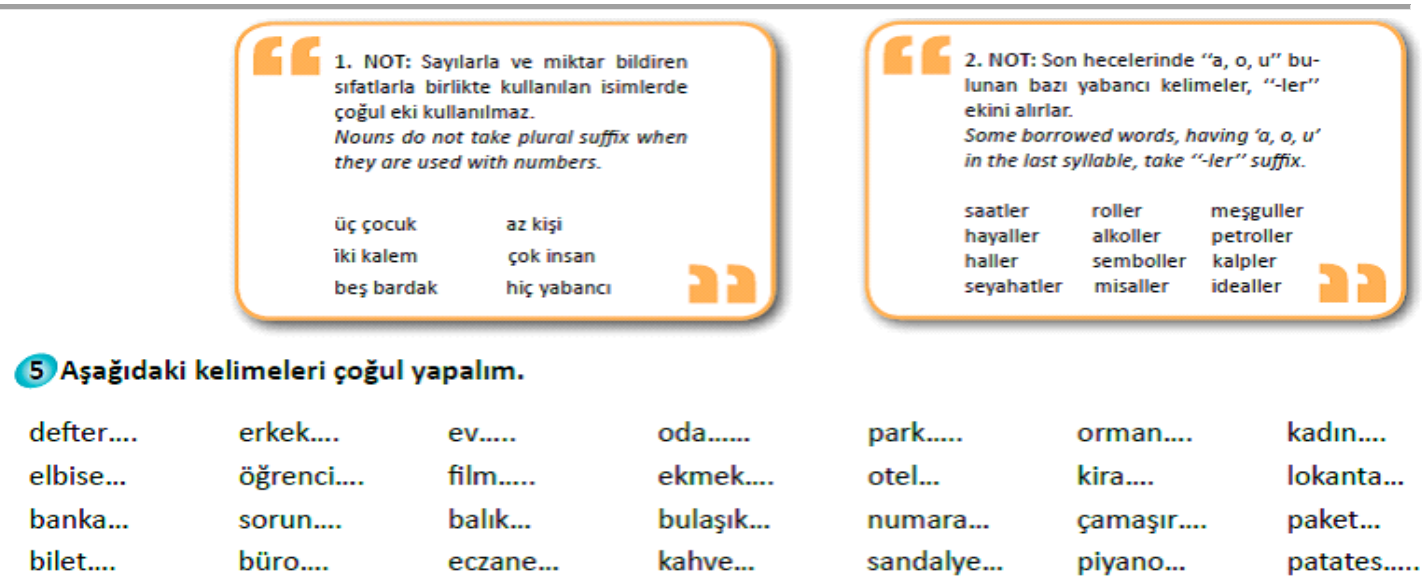

İstanbul Yabancılar İçin Türkçe Ders Kitabı, s. 16

Yedi İklim Türkçe Ders Kitabı (A1):

Yedi İklim Türkçe Ders kitabı, yabancılara Türkçe öğretmek amacıyla yazılan diğer setler gibi A temel seviyede iki, B orta seviyede iki, C ileri seviyede iki ders (Bazı setlerde her seviyede sadece bir kitap vardır.) kitabından oluşmaktadır. Bu sette çokluk eki, temel seviyede A 1 ders kitabında verilmektedir. Çokluk ekinin görevi, örneklerle sezdirilmeye çalışılmış, bilgi verilmeden küçük bir tabloyla ( a, 1, o, u-lar; e, i, ö, ü -ler) kalınlık incelik uyumu gösterilmektedir (s.29). Ardından dört görsel verilerek öğrencilerden bu görsellerdeki adların tekil ve çoğul şekillerini yazması beklenmektedir. Konu "sayılar"1n öğretiminden sonra verilmiş, çokluk bildiren sayı sıfatlarından sonra çokluk ekinin kullanılmadığı örnekle sezdirilmeye çalışılmaktadır. Çokluk konusu işlenmeden önce metinlerde "iyi günler, iyi akşamlar, iyi geceler" gibi kalıp ifadeler ve bir diyalog içinde "Hoşça kalın kızlar!" ifadesi geçmektedir. İstanbul kitabından farklı olarak "Zamirler" konusu diğer ünitede yer almakta anlatım esnasında ekin adı belirtilmeden sadece işlevi sezdirilmeye çalışılmaktadır.
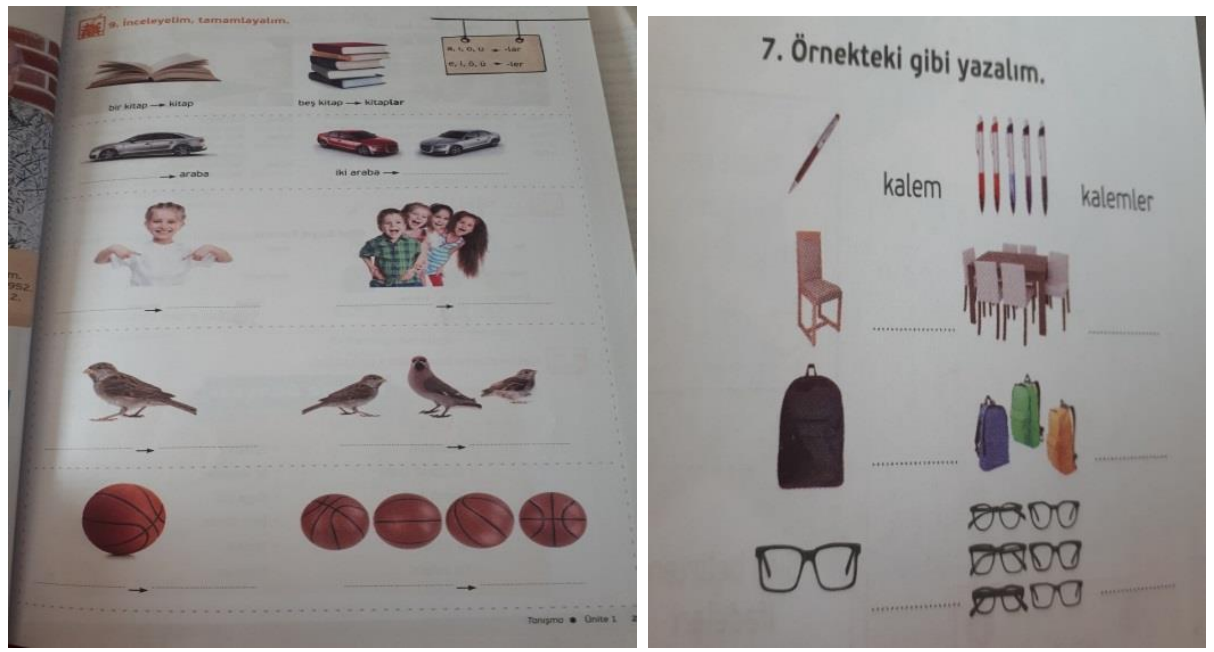

Yedi İklim Türkçe Ders Kitabı Sayfa 29 
Buraya kadar incelenen iki kitabın çokluk ekini nasıl ele aldığı kitaptaki bölümlerin görselleriyle ifade edilmeye çalışılmıştır. Aşağıda, bu iki kaynak kitap ve diğer çalışmada ele alınan kaynakların özellikleri tablo olarak verilmekte ve dört kitap karşılaştırılmaktadır:

Tablo 1: Çokluk Ekinin Gösterildiği Dil Seviyesi, Ünite ve Sayfa Numaras1

\begin{tabular}{lll}
\hline & İstanbul Yabancılar İçin Türkçe & Yedi İklim Türkçe \\
\hline Ekin Verildiği Dil Seviyesi & A1 & A1 \\
\hline Ekin Verildiği Ünite ve Sayfa & Merhaba, sayfa 15-16 & Tanışma, sayfa 29 \\
Ekin Verildiği Konunun Adı & Bu ne? / O kim? & Karşlaşma-Selamlaşma \\
\hline
\end{tabular}

Tablo 2: Çokluk Ekinin Gösterildiği Dil Seviyesi, Ünite ve Sayfa Numarası (Kılıç Vd.: 2014)

\begin{tabular}{lll}
\hline & $\begin{array}{l}\text { Yeni Hitit Yabancılar İçin Türkçe Ders } \\
\text { Kitabı 1 }\end{array}$ & Lale Türkçe Ders Kitabı 1 \\
\hline $\begin{array}{l}\text { Ekin Verildiği } \\
\text { Dil Seviyesi }\end{array}$ & $\mathrm{A} 1 / \mathrm{A} 2$ & $\mathrm{~A} 1$ \\
\hline $\begin{array}{l}\text { Ekin Verildiği } \\
\text { Ünite ve Sayfa }\end{array}$ & Ünite öncesi, Sayfa 7 & 2.Ünite, Sayfa 39 \\
\hline $\begin{array}{l}\text { Ekin Verildiği } \\
\text { Ünitenin Adı }\end{array}$ & Alfabe ve Saylar & Okul \\
\hline
\end{tabular}

Çokluk ekinin verildiği dil seviyesine göre kitaplar karşılaştırıldığında, A temel seviyede hepsinin bu konuyu ele aldığı seviye yönünden farklılık olmadığı görülmektedir. Burada "Yeni Hitit" ders kitabının diğer kaynaklardan daha önce, ünite öncesi hazırlıkta konuyu ele aldığ 1 görülmektedir. Kitap her ne kadar A1/A2 olarak verilse de konu A1 içeriğinde verilmektedir. "İstanbul" ve "Yedi İklim" konuyu ilk ünitenin içinde ele alırken "Lale Türkçe" kitabı ise ikinci ünitenin içinde ele aldığı için diğerlerine göre konuyu geç vermektedir.

Tablo 3: Çokluk Ekinin Gösterilișindeki Konu İçeriği ve Sıralaması (Kılıç Vd.: 2014)

\begin{tabular}{|c|c|c|}
\hline & İstanbul Yabancılar İçin Türkçe & Yedi İklim Türkçe \\
\hline $\begin{array}{l}\text { Konu } \\
\text { içeriğinin } \\
\text { verilişi }\end{array}$ & $\begin{array}{l}\text { 1. Eklendiği kelimeye çokluk anlamı katması } \\
\text { ve ses değişiminin gösterilmesi. } \\
\text { 2. İşaret zamirleriyle çokluk ekinin } \\
\text { kullanımının gösterilmesi. } \\
\text { 3. Sayılarla ve miktar bildiren sıfatlarla birlikte } \\
\text { çoğul ekinin kullanılmaması ( üç çocuk, az } \\
\text { kişi...). } \\
\text { 4. Son hecelerinde "aa, o, u" bulunan bazı } \\
\text { yabancı kelimelerin sadece “-ler" ekini } \\
\text { alması (saatler, roller, meşguller...) }\end{array}$ & $\begin{array}{l}\text { 1. Eklendiği kelimeye çokluk } \\
\text { anlamı katması ve ses } \\
\text { değişiminin gösterilmesi. } \\
\text { 2. Sayılarla çoğul ekinin } \\
\text { kullanılmaması. }\end{array}$ \\
\hline $\begin{array}{l}\text { Konu } \\
\text { içeriğindeki } \\
\text { sıralama }\end{array}$ & $\begin{array}{l}\text { 1. İşaret Zamiri } \\
\text { 2. Çoğul eki (-1Ar) } \\
\text { 3. Soru eki (mI) }\end{array}$ & $\begin{array}{ll}\text { 1. } & \text { İşaret zamirleri } \\
\text { 2. } & \text { Soru eki (mI) } \\
\text { 3. } & \text { "Var/yok" İsim cümleleri } \\
\text { 4. } & \text { Bulunma Hâl eki } \\
\text { 5. } & \text { Sayıllar } \\
\text { 6. } & \text { Çokluk }\end{array}$ \\
\hline
\end{tabular}


Tablo 4: Çokluk Ekinin Gösterilişindeki Konu İçeriği ve Sıralaması

\begin{tabular}{|c|c|c|}
\hline \multicolumn{3}{|c|}{ Tablo 2: Çokluk ekinin gösterilișindeki konu içeriği ve konu içeriğine göre sıralama } \\
\hline & $\begin{array}{l}\text { Yeni Hitit Yabancılar İçin Türkçe } \\
\text { Ders Kitabı } 1\end{array}$ & Lale Türkçe Ders Kitabı 1 \\
\hline Konu içeriği verilişi & $\begin{array}{l}\text { 1. Eklendiği ada çokluk anlamı } \\
\text { katması ve ses değişiminin } \\
\text { gösterilmesi. } \\
\text { 2. Kiși zamirinde çokluk ekinin } \\
\text { gösterimi. }\end{array}$ & $\begin{array}{l}\text { 1. Çokluk ekinin şahıs zamiri } \\
\text { ile kullanımı } \\
\text { 2. İşaret zamirleri ile çokluk } \\
\text { eki kullanılması } \\
\text { 3. Eklendiği kelimeye çokluk } \\
\text { anlamı katması ve ses } \\
\text { değişiminin gösterilmesi }\end{array}$ \\
\hline Konu içeriğindeki sıralama & $\begin{array}{l}\text { 1.Çokluk eki } \\
\text { 2.Kiși zamirleri }\end{array}$ & $\begin{array}{l}\text { 1.Kişi zamirleri } \\
\text { 2.İşaret zamirler } \\
\text { 3.Çokluk eki }\end{array}$ \\
\hline
\end{tabular}

Çokluk ekinin anlatımında verilen hususlar bakımından kitaplar karşılaştırıldığında, "Lale Türkçe" kitabında konu başlığının(Çokluk Eki) altında ekin, eklendiği kelimeye çokluk anlamı katmasının ve bu kelimedeki ses değişiminin ele alındığı görülmektedir. Ancak konuyu anlatmadan birinci ünitede şahıs zamirlerinin ve ikinci ünitede işaret zamirlerinin çokluk hâlleri de verilmektedir. Ayrıca diğer kitaplardan farklı olarak bu kitapta çokluk ekinden önce " iyelik ekleri”, "isimlerde olumsuzluk" konuları verilmektedir. Konuyula ilgili alıştırma bulunmamaktadır.

"Yeni Hitit" de konu başlığı altında eklendiği kelimeye çokluk anlamı katması ve ses değişimi verilmekle birlikte konunun devamında kişi zamirlerinin çokluk hâlleri verilmektedir. Konuyla ilgili alıştırma bulunmaktadır.

"Yedi İklim Türkçe" ders kitabı da konuyu ele alış yönüyle "Yeni Hitit" kitabıyla benzerlik göstermektedir. Eklendiği kelimeye çokluk anlamı katması ve ses değişimi gösterilmektedir. Ayrıca ekin sayılarla kullanımını da vererek sayılardan sonra çokluk ekinin kullanılmadığı sezdirilmeye çalışılmaktadır. Konu işaret zamirlerinden sonra ele alındığı için işaret zamirlerinin sadece teklik şekilleri verilmektedir. Konuyla ilgili alıştırmalar kitapta bulunmaktadır.

"İstanbul Yabancılar İçin Türkçe" kitabında çokluk ekinin işaret zamirlerinden sonra yer aldığ1 ancak iki konunun birbiriyle bütünleşik olarak verildiği görülmektedir. Zamirlerin çokluk şekilleri de çokluk ekinin hemen yanında gösterilmektedir. Kitap diğerlerine göre konuyu daha kapsamlı ele almaktadır. Kitapta, ekin sadece eklendiği kelimeye çokluk anlamı katması ya da ses değişimleri değil; sayılarla, sıfatlarla kullanımı, istisna kelimelerin tek şekilli ek alması da vurgulanmaktadır. Bu yönüyle konuyu detaylı ele alması yönüyle "İstanbul Yabancılar İçinTürkçe" diğerlerinden ayrılmaktadır. Kitapta konuyla ilgili alıştırmalar da bulunmaktadır.

Çokluk ekinin, Türkçeyi yabancı dil olarak öğrenen öğrencilere öğretimi sırasında genellikle adları çoğul yapma işlevinin vurgulanmakta olduğu, büyük ünlü kuralına ait özelliklerin verildiği (kalın ünlüden sonra -lar/ ince ünlüden sonra -ler), istisna kelimeler üzerinde durulduğu (saat-ler, harf-ler, sembol-ler...) ve sayı sıfatlarından sonra bu ekin kullanılmadığının belirtildiği ise incelenen kitaplarda görülmektedir. Türkçeyi yabancı dil olarak öğrenen öğrencilerin A temel seviyede çokluk ekiyle ilgili yaşadıkları sıkıntılar ise şöyle sıralanabilir:

1. Ne zaman kalın ne zaman ince ünlü kullanacaklarını bilememek

2. İstisna kelimelerin çokluk ekiyle kullanımını karıştırmak

3. Sayı ve belgisizlik belirten bazı sıfatlardan sonra çokluk ekini kullanmaktır. Bu hatalar, öğrencilerin yazma becerileri üzerine yapılan bazı çalışmalarda ele alınmaktadır ve bu çalışmalarda 
çokluk ekinin, hâl ekleri ve tamlama eklerinden sonra öğrencilerin en fazla hata yaptıkları çekim eki olduğu ifade edilmektedir ( Şahin: 2013; Ak Başoğul ve Can: 2012). Orta ve ileri seviyeye geldikleri zaman ise "dayımlar ve dayılarım" arasındaki farkı ayırt edememe,"Fatihler bize geldi." gibi cümlelerde özel isimle birlikte kesme işaretini kullanarak noktalama yanlışına düşme, öğrencilerin çokluk ekiyle ilgili hatalarından sayılabilir.

\section{Sonuç ve Öneriler}

Bu çalışmada, çokluk ekinin Türkçenin yabancı dil olarak öğretimi için yazılan kitaplarda ele alınışı incelenmiş, eksik kalan noktalar tespit edilmeye çalışılmıştır. Ayrıca çokluk ekinin ele alındığ 1 farklı kitaplar da taranmaya çalışılmış, çokluk ekinin geçmişten günümüze nasıl kullanıldığının İlhan (2009)'a ait “ Türk Dilinde Çokluk” adlı kitapta mevcut olduğu görülmüştür. Yabancılara Türkçe öğretiminde çokluk eki üzerine yapılan başka bir çalışmada (Kılıç vd.: 2014) da "Yeni Hitit Yabancılar İçin Türkçe" ve "Lale Yabancılar İçin Türkçe Ders Kitabı" incelendiği tespit edilmiş, bu çalışmada çokluk ekinin (dil bilgisi konusu olarak) anlatımındaki sıralama farklılıklarının üzerinde durulduğu ve sonuç olarak çokluk ekinin dil bilgisi konuları içerisinde ön sıralarda verilmesi konusunda kaynaklar arasında birlik sağlanması gerektiği vurgulanmıştır. Çalışmaya başlarken Türkçenin yabancı dil olarak öğretimi için yazılan kitaplardan ikisinin, "çokluk" ekini ele alışları yönünden incelenmiş olması bizi diğer kitapları incelemeye yönlendirmiştir. $\mathrm{Bu}$ sebeple bulgular kısmında diğer çalışmanın bulguları da değerlendirilmiştir. Çokluk ekiyle ilgili daha önce yapılan çalışmayla hemfikir olmakla birlikte bu çalışmada özellikle dikkat çekmek istediğimiz nokta çokluk ekinin dil bilgisi sıralamasında kaçıncı sırada verilmesi gerektiği değil; ekin kelimeye kattığı farklı anlam özelliklerinin de dil öğretiminde verilmesi gerektiğidir.

Çokluk ekinin anlatımında verilen hususlar bakımından kitaplar karşılaştırıldığında, "Lale Türkçe" kitabının konu başlığı (Çokluk Eki) altında, çokluk ekinin eklendiği kelimeye çokluk anlamı katmasını ve ses değişimini ele aldığı görülmektedir. Ancak konuyu anlatmadan birinci ünitede şahıs zamirlerinin ve ikinci ünitede işaret zamirlerinin çokluk hâlleri de verilmektedir. Çokluk ekinin konu sıralaması olarak ikinci ünitede yer alması hem konunun gecikmesine hem de konu anlatılmadan farklı yapılarla kullanılmasına sebep olmuştur. Çokluk ekinin öğretimi yapılmadan kitapta zamirlerin çokluk şekillerine de yer verilmiştir. Diğer üç kitapta böyle bir problemle karşılaşılmamıştır. "Yeni Hitit" de konu başlığı altında çokluk ekinin eklendiği kelimeye çokluk anlamı katması ve ses değişimi verilmekle birlikte konunun devamında kişi zamirlerinin çokluk hâlleri de verilmektedir. Genel olarak kitapların çokluk ekini ele alışları aynı doğrultuda olmakla birlikte "İstanbul Yabancılar İçin Türkçe" kitabında istisna kelimelerin verilmesi, ekin belirsizlik sıfatıyla ve sayılarla kullanımının da vurgulanması kitabın daha fazla bilgi içerdiğini ortaya koymaktadır. Bu hususların öğrencilerin A seviyede hata yaptıkları hususlar olması da, kitaplarda bu konuların verilmesini gerekli kılmaktadır.

Yeni Hitit ve Lale kitaplarında da çokluk ekinin anlatımı İstanbul ve Yedi İklim kitaplarıyla benzerlik göstermektedir. Bu kitaplarda da ekin diğer işlevleri anlatılmamıştır. A temel seviyede Türkçe öğrenen yabancı bir öğrenciye çokluk ekinin diğer anlam özelliklerini anlatmak hem zor hem de temel seviye için gereksizdir. Ancak ekin kelimeye kattı̆g 1 farklı anlam özelliklerinin de dil öğretiminde verilmesi gerekmektedir. Dilbilimi de dil incelemelerine çok katmanlı yaklaşarak dilde yapı-anlam-işlev boyutlarını başta yabancı dil öğretimi bağlamında özenle vurgulamaktadır (Erdem, Çelik: 2011). Bazı dil bilgisi kuralları çatallı bir yapıya sahiptir. Çatalın temel kısmını A temel seviyede anlatmak mümkünken çatalın dişleri dediğimiz diğer anlam özelliklerini ya da işlevlerini farklı seviyelerde vermemiz gerekmektedir. Bu sebeple çokluk eki başta olmak üzere bu yapıda olan dil bilgisi kuralları tespit edilerek temel kurallar, temel seviyede diğer işlevleri farklı seviyelerde olacak şekilde, dil bilgisi kuralları özellikle yabancılara Türkçe öğretiminde yeniden gözden geçirilmelidir. Çokluk ekinin bazı belgisiz sıfatlardan sonra (hiç hiçbir, birkaç, az - biraz, çok - birçok, çoğu, her, herhangi bir) kullanılmadığı orta seviye bitmeden 
öğrencilere öğretilmelidir. Ekin diğer anlam özellikleri özellikle iyelik ekinden sonraki aile anlamı (-gil), abartma anlamı, yaklaşıklık anlamı, yıl anlamı mutlaka orta seviyede anlama metinlerinin içinde kullanılmak suretiyle öğrencilere verilmelidir. Yabancılara Türkçe öğretimi için yazılan kitap setlerinin öğretmen kılavuz kitaplarında eklerin çatallılık (çok boyutluluk) özelliğine vurgu yapılmalı, eklere ait farklı işlevlerin hangi seviyelerde verileceği belirtilmelidir.

Dil bilgisi bir beceri olmasa da yabancı bir dilin öğrenilmesini ve öğretilmesini kolaylaştıran bir destektir. Her dilin yapısı ve dil bilgisel önceliği birbirinden farklı olduğu için dil bilgisi öğretiminde Türk dilinin yapısı düşünülerek standart bir sıralamaya gidilmelidir (Yeşilyurt, 2018). Bu sıralamada yapıların anlam özellikleri ele alınmalı, yabancılara Türkçe öğretiminde hangi anlam özelliğinin hangi seviyede verileceği tartışılmalı ve ortak bir karara bağlanmalıdır. Türkçenin yabanc1 dil olarak öğretiminde eklerin işlev özelliklerinin yanı sıra kelimeye kazandırdıkları anlam özellikleri üzerinde de durulmalı eklerin farklı anlam yönlerine vurgu yapacak cümle örnekleri mutlaka verilmelidir.

Dil bilgisi kitaplarında ele alınan bazı konular temel seviyede verildikten sonra öğrencinin dil seviyesi geliştikçe diğer seviyelerde detaylandırılarak verilmelidir. -1Ar çokluk ekinin abartma anlamını, temel seviyedeki öğrenciye anlatmak ve öğretmek zor ve gereksiz olabilir ancak öğrencinin seviyesi ilerledikçe -1Ar ekinin eklendiği kelimeye farklı anlamlar da kattığını öğretmek bir zorunluluktur.

\section{Kaynakça}

Ak Başoğul, D. ve Can, F. S. (2014). "Yabancı dil olarak Türkçe öğrenen Balkanlı öğrencilerin yazılı anlatımında yaptıkları hatalar üzerine tespitler." Dil ve Edebiyat Eğitimi Dergisi, 10, 100-119.

Banguoğlu, T. (1998). Türkçenin Grameri. Türk Dil Kurumu Yay.

Çepni, S. (2007). Araştırma ve Proje Çalışmalarına Giriş. Pegem A Yay.

Doğru, F. (2017). $+\{l A r\}$ Biçimbiriminin Dilek/Temenni İşlevi Üzerine. Malatya: IX. Uluslararas1 Dünya Dili Türkçe Sempozyumu Bildiri Kitabı.

Erdem İ ve Çelik M. (2011). "Dil Bilgisi Öğretim Yöntemi Üzerine Değerlendirmeler.” Turkish Studies - International Periodical For The Languages, terature and History of Turkish or Turkic Volume, 6(1) : 1057-1069.

Ergin M.(2005). Türk Dil Bilgisi. Bayrak Basım Yayım Tanıtım.

Kaptan, S. (1998). Bilimsel Araştırma ve İstatistik Teknikleri. Tekışık Yay.

Karasar, N. (2010). Bilimsel Araştırma Yöntemi. Nobel Yayın Dağıtım.

Kılıç, F, Erdem, M, Gün ve Çaydas, A. (2014). "Yeni Hitit Yabancılar İçin Türkçe Ders Kitabı 1 Ve Lale Türkçe Ders Kitabı 1'de Çokluk Ekinin Kullanım Özellikleri Üzerine Bir Değerlendirme." Journal of Educational Science, 2(2), 56-65. Retrieved from https://dergipark.org.tr/tr/pub/jedus/issue/16125/168711.

Korkmaz, Z. (2003). Türkiye Türkçesi Grameri. TDK Yayınlanı.

Kuznetsov, Petro İ. (1997). Türkiye Türkçesinin Morfoetimolojisine Dair. Ankara: TDK Yayınları

Nadir, İ.(2009). Türk Dilinde Çokluk. Manas Yayıncılık. 
Şahin, E. Y.(2014). "Yabancı Dil Olarak Türkçe Öğrenen Öğrencilerin Yazılı Anlatımlarındaki Ek Yanlışları." Tarih Okulu Dergisi (TOD), 6(15):433-449.

Yeşilyurt, Ş.(2018). "Yabancı Dil Olarak Türkçe Öğretiminde “-Dı1k” ve “- An” Sıfat Fiil Ekiyle Yapılan Cümle Birleştirmelerini Cümle Ögesi ve Zaman Ekine Göre İnceleme.” Turkish Studies Educational Sciences, 13(27): 1693-1710. 